BMJ Open

Diabetes

Research

\& Care

\section{Factors associated with high oxidative stress in patients with type 2 diabetes: a meta-analysis of two cohort studies}

To cite: Anusruti A, Xuan Y, Gào $\mathrm{X}$, et al. Factors associated with high oxidative stress in patients with type 2 diabetes: a meta-analysis of two cohort studies. BMJ Open Diab Res Care 2020;8:e000933. doi:10.1136/ bmjdrc-2019-000933

- Additional material is published online only. To view please visit the journal online (http://dx.doi.org/10.1136/ bmjdrc-2019-000933).

Received 26 September 2019 Revised 10 December 2019 Accepted 15 January 2020

A Check for updates

C) Author(s) (or their employer(s)) 2020. Re-use permitted under CC BY-NC. No commercial re-use. See rights and permissions. Published by BMJ.

1 Division of Clinical Epidemiology and Ageing Research, German Cancer Research Center, Heidelberg, Germany

${ }^{2}$ Network Aging Research, University of Heidelberg, Heidelberg, Germany ${ }^{3}$ Centre for Health Protection, National Institute of Public Health and the Environment, Bilthoven, The Netherlands

Correspondence to Dr Ben Schöttker b.schoettker@dkfz.de

\section{ABSTRACT}

Objective Our objective is to identify the potential factors associated with serum Diacron's reactive oxygen metabolites test (D-ROM) levels of patients with type 2 diabetes mellitus (T2DM) by conducting cross-sectional and longitudinal analyses in two large cohorts and further strengthening these results by performing a meta-analysis. Methods Serum D-ROM concentrations were measured in 1045 and 1101 patients with T2DM from two independent cohort studies from Germany at baseline and repeatedly 3-4 years later. The cross-sectional and longitudinal associations of various potential determinants with D-ROM levels were assessed with a backwards selection algorithm in multivariable adjusted models.

Results In the meta-analysis of the cross-sectional analysis, female sex, low education, obesity, smoking, high total cholesterol, hemoglobin $A_{1 \mathrm{c}} \geq 7 \%$, no diabetes medication, a history of myocardial infarction, heart failure, a history of cancer and $C$ reactive protein levels (CRP) $>3 \mathrm{mg} / \mathrm{L}$ were statistically significantly associated with increased D-ROM levels in patients with T2DM. The meta-analysis of the longitudinal analysis revealed that old age, female sex, obesity, smoking, physical inactivity, high alcohol consumption, $\geq 5$ years since diabetes diagnosis and CRP levels between $3 \mathrm{mg} / \mathrm{L}$ and $10 \mathrm{mg} / \mathrm{L}$ were statistically significantly associated with D-ROM levels measured 3-4 years later.

Conclusions (validity, limitations and clinical applicability) This comprehensive analysis confirmed that several modifiable risk factors are being associated with oxidative stress in patients with T2DM within an observational study design. We discuss potential prevention measures against these risk factors that might help to reduce oxidative stress and to prevent some cases of premature mortality in patients with T2DM.

\section{BACKGROUND}

Oxidative stress (OS) can be termed as any imbalance between the production of reactive oxygen species (ROS) and antioxidant defenses resulting in tissue damage. ${ }^{1}$ High levels of OS are already known to be a partaker in progressing cell senescence and resulting in aging-related diseases, ${ }^{2}$ like type 2 diabetes mellitus (T2DM), ${ }^{3}{ }^{4}$ cancer and various diseases of cardiovascular, neurological and cognitive origin. ${ }^{5}$ OS can contribute to the

\section{Significance of this study}

What is already known about this subject?

- Oxidative stress is a driving force in the pathophysiology of type 2 diabetes mellitus (T2DM). The Diacron's reactive oxygen metabolites test (D-ROM) serum concentration has recently been shown to be strongly associated with mortality in patients with T2DM.

\section{What are the new findings?}

- To the best of our knowledge, no study has comprehensively investigated the potential risk factors for high oxidative stress among patients with T2DM so far.

- We investigated associations of 22 potential determinants with high oxidative stress among patients with T2DM of two large cohort studies both in crosssectional and longitudinal analysis and conducted meta-analyses.

- The meta-analysis of the longitudinal analysis revealed that old age, female sex, obesity, smoking, physical inactivity, high alcohol consumption, $\geq 5$ years since diabetes diagnosis and $\mathrm{C}$ reactive protein levels between $3 \mathrm{mg} / \mathrm{L}$ and $10 \mathrm{mg} / \mathrm{L}$ were statistically significantly associated with D-ROM levels measured 3-4 years later.

How might these results change the focus of research or clinical practice?

- This comprehensive analysis confirmed that several modifiable risk factors are being associated with oxidative stress in patients with T2DM. We discuss potential prevention measures against these risk factors that might help to reduce oxidative stress and to prevent some cases of premature mortality in patients with T2DM.

course of T2DM by increasing insulin resistance via disruption of the insulin signaling pathway and by contributing to an impairment of pancreatic beta cell function ${ }^{67}$ Thus, OS is believed to play a role in the development of diabetes complications. ${ }^{8-10}$

Recently, our group showed that the OS biomarker Diacron's reactive oxygen metabolites test (D-ROM) was strongly associated 
with the mortality of patients with T2DM. ${ }^{10}$ This test measures OS by detecting molecules with hydroperoxide groups (chemical: R-O-O-H) in serum or plasma. ${ }^{11}$ D-ROM is mainly a biomarker of lipid peroxidation and has been demonstrated to be very stable in blood samples stored for many years. ${ }^{12}$

To the best of our knowledge, no single study has comprehensively investigated major potential determinants of OS in patients with T2DM so far. We, therefore, conducted cross-sectional and longitudinal analyses in two large cohorts of patients with T2DM to identify the factors associated with serum D-ROM levels. Results were pooled in individual patient data meta-analyses to increase the statistical power and to minimize the risk of detection of statistically significant associations by chance in single studies.

\section{METHODS}

\section{Study design}

The current study is an individual patient data metaanalysis of two prospective, German cohort studies, namely the ESTHER study (German name: 'Epidemiologische Studie zu Chancen der Verhütung, Früherkennung und optimierten Therapie chronischer Erkrankungen in der älteren Bevölkerung') ${ }^{13}$ and the DIANA study (German name: Diabetes mellitus: Neue Wege der Optimierung der allgemeinen ärztlichen Betreuung). ${ }^{14}$

The ESTHER study is an ongoing, population-based cohort study from the South-Western German federal state Saarland and is being conducted among older adults aged between 50 years and 75 years. ${ }^{13}$ The baseline examination was implemented in 2000-2002 when the 9949 participants were enrolled by their respective general practitioners (GPs) during a routine health examination. Follow-up (FU) examinations were carried out 2, 5, 8, 11 and 14 years after baseline via self-administered questionnaires filled out by the participants and their respective GPs. Additionally, blood samples were collected at the 5-year, 8-year, 11-year and 14-year FU, and home visits were conducted at the 8-year, 11-year and 14-year FU. The home visits were conducted by trained study physicians, lasted approximately 3 hours, and were used to collect further detailed information via pharmacological, geriatric, cognitive and anthropometric examinations. ${ }^{15}$

The DIANA study included 1158 patients diagnosed with T2DM who were 18 years or older at baseline (93.7\% were older than 40 years). Study participants were recruited by their GP in accordance with a standardized protocol between October 2008 and March 2010 in the Ludwigsburg-Heilbronn area situated in South-West Germany. ${ }^{14}$ Study participants were re-examined 4 and 7 years after baseline. In addition to the sociodemographic characteristics reported by patients, the GPs also filled questionnaires with questions about diabetes treatment and comorbidities. In addition, blood samples were collected at baseline, 4-year and 7-year FU.

\section{Inclusion and exclusion criteria}

The schematic presentation of the study populations used in the cross-sectional and longitudinal analysis is shown in figure 1. For the ESTHER study, 8-year FU data served as the baseline and 11-year FU data were considered as the FU measurement for this research project. From 9949 total ESTHER participants, 6020 participated again in the 8-year FU. Subsequently, 4633 study participants $(76.9 \%)$ were excluded as they did not have a physician-reported diabetes diagnosis or self-reported use of antidiabetic medication. Additionally, 25 potentially type 1 diabetes cases (diabetes diagnosis was before the age of 40 years) were excluded, resulting in a T2DM patient population of $n=1362$. Furthermore, 317 subjects without D-ROM data (in most cases because of a missing blood sample) were excluded, resulting in a sample size of 1045 for the cross-sectional analyses. Additionally, 314 subjects were excluded for longitudinal study as they lacked 11-year D-ROM measurements because of missing repeated blood samples. Thus, 731 participants were finally included for the longitudinal analyses.

For the DIANA study, baseline measurements served as the basis for the cross-sectional study, and the 4-year FU data were considered as the FU measurements for the longitudinal analysis. Out of the 1158 baseline participants, 19 participants aged 40 years and younger (potential type 1 diabetes) were not considered and 38 were excluded due to lack of baseline D-ROM measurements, resulting in $\mathrm{n}=1101$ patients with T2DM to be included in the cross-sectional analyses. For the longitudinal analysis, 361 subjects were excluded as they lacked 4-year FU D-ROM measurements due to missing repeated blood samples, leaving 740 study participants. Among the included sample from the DIANA cohort, no study participant reported a diabetes diagnosis before the age of 40 years, and we assumed that all included study participants are patients with T2DM.

\section{D-ROM measurements}

Serum samples from both studies were shipped to the Laboratory for Health Protection Research (Bilthoven, the Netherlands), in which the assay used to measure D-ROM (Diacron, Grosseto, Italy) was adapted to an autoanalyzer (LX20-Pro, Beckman-Coulter, Woerden, the Netherlands). ${ }^{16}$ The assay measures Caratelli units (Carr U) and 1 Carr $\mathrm{U}$ corresponds to $0.08 \mathrm{mg} \mathrm{H}_{2} \mathrm{O}_{2} / \mathrm{dL}$ in serum. Based on the distribution of D-ROM levels in 5000 healthy Italians, Diacron suggested to define 'high OS' by D-ROM levels $>400$ Carr U. We use this definition of 'high OS' in this research project because D-ROM levels above this cut-off were shown to be associated with mortality in a large meta-analysis of cohort studies with older adults from the general population. ${ }^{17}$

\section{Assessment of potential determinants of OS}

As we aim to present a broad overview of potential risk factors for high OS among patients with T2DM, all assessed variables in the two studies, which are directly 


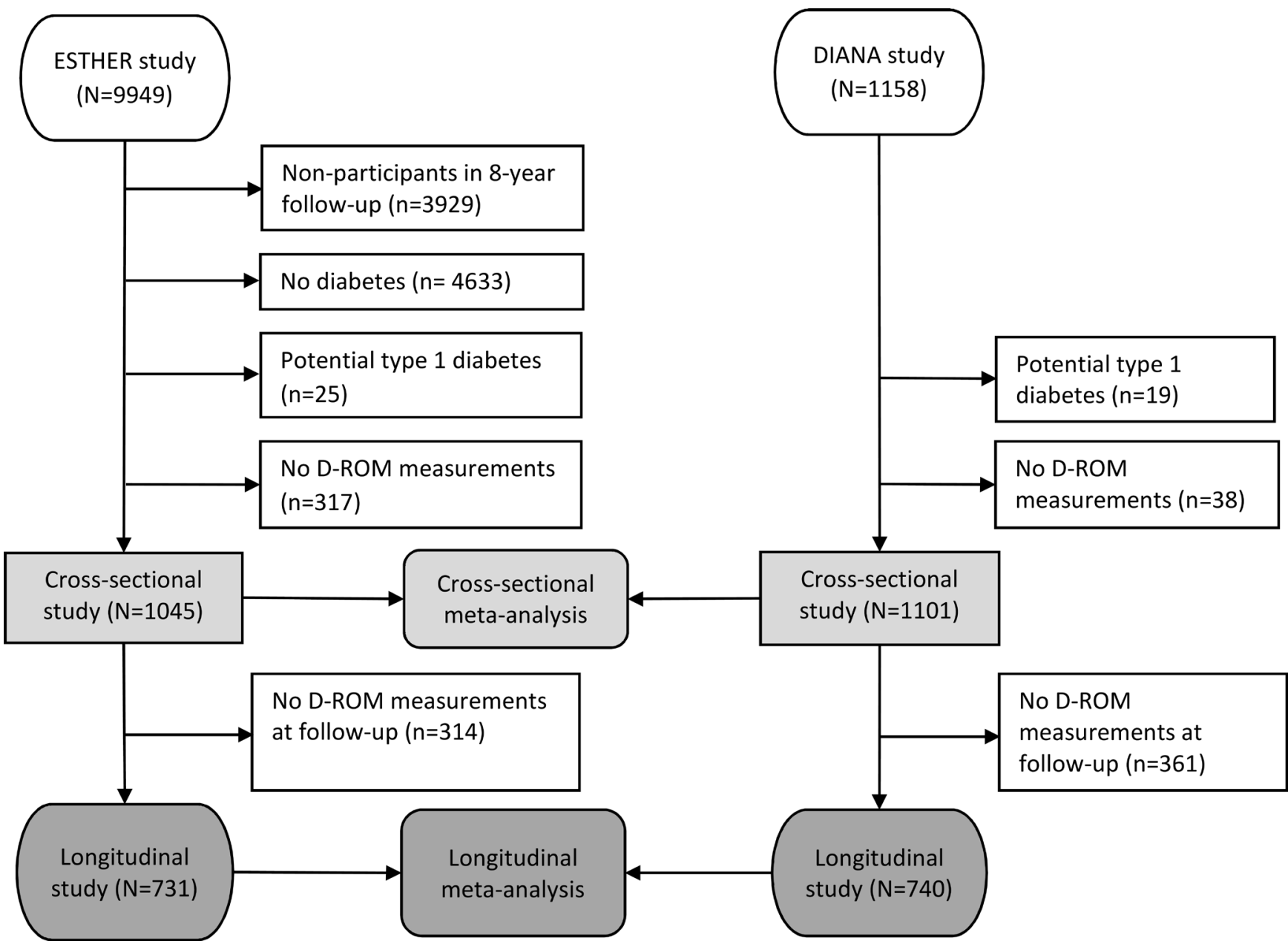

Figure 1 Flow chart of ESTHER and DIANA study participants for cross-sectional and longitudinal study. DIANA, Diabetes mellitus: Neue Wege der Optimierung der allgemeinärztlichen Betreuung; D-ROM, Diacron's reactive oxygen metabolites test; ESTHER, Epidemiologische Studie zu Chancen der Verhütung, Früherkennung und optimierten Therapie chronischer Erkrankungen in der älteren Bevölkerung.

or indirectly related to the lifestyle or health status, were selected as potential determinants. The chosen sociodemographic and lifestyle factors were age, sex, education, smoking, physical activity, alcohol consumption, vegetable consumption, fruit consumption and body mass index (BMI), and they were all retrieved from the study participants' standardized questionnaires.

The question about physical activity was in the ESTHER study was: 'How many hours per week are you on average been physically active (at work and during leisure time combined) at present?'. The information about vigorous physical activity (eg, sport) has been used to code the following dichotomous variable: inactive: 0 hour of vigorous physical activity/week; active: $>0$ hour of vigorous physical activity/week. The question on vigorous physical activity in the DIANA study was: 'On how many of the last 7 days did you do vigorous physical activity?'. If the answer was 'Not at all in last 7 days', participants were grouped into the 'inactive' category. The question on alcohol consumption in both studies was similar: 'How much alcohol did you drink on average per week ... (ESTHER: ' $\ldots$ at present'; DIANA: '.. in last 12 months')?'. The information on the numbers of bottles of beer, glasses of wine, and shots of spirits have been used to calculate the consumption of grams of ethanol per day. Subsequently, WHO categories of low, moderate and high alcohol consumption have been coded (see legend of table 1 for details). Dietary information was assessed in both studies with one question: 'How often did you consume the following food and drinks in the last 12 months on average?'. In this analysis, we combined study participants, who answered 'several times per day' or 'once per day' in the category 'daily consumers', and all other answer categories (which differed in the two studies but all described frequencies less often than daily consumption) were combined in the category "non-daily consumers'.

Selected medical diagnoses and major past disease events were coronary heart disease (CHD), heart failure, hypertension, myocardial infarction (MI), stroke and cancer. Information on the medical history was taken from the physicians' questionnaires. The only exception was cancer in the ESTHER study, which was recorded by the cancer registry of Saarland. 
Table 1 Baseline characteristics of the ESTHER diabetes subcohort and the DIANA cohort

\begin{tabular}{|c|c|c|}
\hline \multirow[b]{3}{*}{ Baseline characteristics } & \multicolumn{2}{|l|}{ Cohorts } \\
\hline & $\begin{array}{l}\text { ESTHER } \\
(n=1045)\end{array}$ & $\begin{array}{l}\text { DIANA } \\
(n=1101)\end{array}$ \\
\hline & $\mathbf{N}(\%)^{*}$ & $\mathbf{N}(\%)^{\star}$ \\
\hline \multicolumn{3}{|l|}{ Age (years) } \\
\hline$<60$ & $57(5.4)$ & $206(18.7)$ \\
\hline $60-<70$ & 441 (42.2) & $313(28.4)$ \\
\hline $70-<80$ & 473 (45.3) & $455(41.4)$ \\
\hline$\geq 80$ & $74(7.1)$ & $127(11.5)$ \\
\hline \multicolumn{3}{|l|}{ Sex } \\
\hline Male & $541(51.8)$ & 605 (54.9) \\
\hline Female & 504 (48.2) & $496(45.6)$ \\
\hline \multicolumn{3}{|l|}{ Education† } \\
\hline Low & $816(78.1)$ & $806(73.2)$ \\
\hline Medium & $130(12.4)$ & $197(17.9)$ \\
\hline High & $99(9.5)$ & $98(9.9)$ \\
\hline \multicolumn{3}{|l|}{ BMI (kg/m²) } \\
\hline$<25$ & $142(13.6)$ & $149(13.5)$ \\
\hline $25-<30$ & 466 (44.6) & $431(39.1)$ \\
\hline $30-<35$ & 305 (29.2) & $340(30.9)$ \\
\hline $35-<40$ & $92(8.8)$ & $108(9.9)$ \\
\hline$\geq 40$ & $40(3.8)$ & $73(6.6)$ \\
\hline \multicolumn{3}{|l|}{ Smoking } \\
\hline Never smoker & $503(48.1)$ & $531(48.2)$ \\
\hline Former smoker & 453 (43.4) & $441(40.1)$ \\
\hline $\begin{array}{l}\text { Current smoker, smoking } \\
0-15 \mathrm{~g} \text { tobacco/day }\end{array}$ & $45(4.3)$ & $65(5.9)$ \\
\hline $\begin{array}{l}\text { Current smoker, smoking } \\
>15 \mathrm{~g} \text { tobacco/day }\end{array}$ & $44(4.2)$ & $64(5.8)$ \\
\hline \multicolumn{3}{|l|}{ Alcohol consumption $\ddagger$} \\
\hline Abstainer & $466(44.5)$ & $402(36.6)$ \\
\hline Low consumption & $533(51.0)$ & $629(57.1)$ \\
\hline Moderate consumption & $33(3.2)$ & $48(4.3)$ \\
\hline High consumption & $13(1.2)$ & $22(2.0)$ \\
\hline \multicolumn{3}{|l|}{ Physical activity§ } \\
\hline Inactive & $582(55.7)$ & $277(25.2)$ \\
\hline Active & $463(44.3)$ & $824(74.8)$ \\
\hline \multicolumn{3}{|l|}{ Daily vegetable consumption } \\
\hline No & 852 (81.6) & $735(66.7)$ \\
\hline Yes & $193(18.4)$ & $366(33.3)$ \\
\hline \multicolumn{3}{|l|}{ Daily fruit consumption } \\
\hline No & 417 (39.9) & 365 (33.2) \\
\hline Yes & $628(60.1)$ & $736(66.8)$ \\
\hline \multicolumn{3}{|l|}{$\mathrm{HbA}_{1 \mathrm{c}}(\%)$} \\
\hline$<6$ & $227(21.7)$ & $151(13.7)$ \\
\hline
\end{tabular}

Table 1 Continued

\begin{tabular}{|c|c|c|}
\hline \multirow[b]{3}{*}{ Baseline characteristics } & \multicolumn{2}{|l|}{ Cohorts } \\
\hline & $\begin{array}{l}\text { ESTHER } \\
(n=1045),\end{array}$ & $\begin{array}{l}\text { DIANA } \\
(n=1101)\end{array}$ \\
\hline & $\mathbf{N}(\%)^{*}$ & $\mathbf{N}(\%)^{*}$ \\
\hline $6-<7$ & $489(46.8)$ & $575(52.2)$ \\
\hline $7-<8$ & $252(24.1)$ & 241 (21.9) \\
\hline$\geq 8$ & $77(7.4)$ & $134(12.2)$ \\
\hline \multicolumn{3}{|l|}{ Diabetes medication } \\
\hline No & 348 (33.3) & $276(25.1)$ \\
\hline Oral antidiabetics & $501(47.9)$ & $592(53.8)$ \\
\hline Insulin & $196(18.8)$ & $233(21.1)$ \\
\hline \multicolumn{3}{|c|}{$\begin{array}{l}\text { Time since diabetes diagnosis } \\
\text { (years) }\end{array}$} \\
\hline$<5$ & $445(42.6)$ & $358(32.5)$ \\
\hline $5-<10$ & $325(31.1)$ & $300(27.3)$ \\
\hline $10-<20$ & 205 (19.6) & $346(31.4)$ \\
\hline$\geq 20$ & $70(6.7)$ & $97(8.8)$ \\
\hline \multicolumn{3}{|l|}{ Renal dysfunction } \\
\hline No & 748 (71.6) & $800(72.6)$ \\
\hline Yes & $297(28.4)$ & $301(27.4)$ \\
\hline \multicolumn{3}{|l|}{ Hypertension } \\
\hline No & $299(28.6)$ & $238(21.6)$ \\
\hline Yes & $746(71.4)$ & $863(78.4)$ \\
\hline \multicolumn{3}{|l|}{ History of stroke } \\
\hline No & $927(88.7)$ & $1035(94.0)$ \\
\hline Yes & $128(11.3)$ & $66(6.0)$ \\
\hline \multicolumn{3}{|c|}{ History of myocardial infarction } \\
\hline No & $916(87.7)$ & $1007(91.5)$ \\
\hline Yes & $129(12.3)$ & $94(8.5)$ \\
\hline \multicolumn{3}{|l|}{ Coronary heart disease } \\
\hline No & 737 (70.5) & $897(81.5)$ \\
\hline Yes & $308(29.5)$ & 203 (18.5) \\
\hline \multicolumn{3}{|l|}{ Heart failure } \\
\hline No & $828(79.2)$ & $963(87.5)$ \\
\hline Yes & $217(20.8)$ & $138(12.5)$ \\
\hline \multicolumn{3}{|l|}{ History of cancer } \\
\hline No & 907 (86.8) & $990(89.9)$ \\
\hline Yes & $138(13.2)$ & $111(10.1)$ \\
\hline \multicolumn{3}{|l|}{ Total cholesterol (mg/dL) } \\
\hline$<200$ & $379(36.3)$ & $392(35.6)$ \\
\hline $200-<280$ & $568(54.3)$ & $568(51.6)$ \\
\hline$\geq 280$ & $98(9.4)$ & $141(12.8)$ \\
\hline \multicolumn{3}{|l|}{ HDL cholesterol (mg/dL) } \\
\hline$<40$ & $158(15.1)$ & $268(24.4)$ \\
\hline $40-<80$ & $840(80.4)$ & $772(70.1)$ \\
\hline$\geq 80$ & $47(4.5)$ & $61(5.5)$ \\
\hline
\end{tabular}

Continued 
Table 1 Continued

\begin{tabular}{ll} 
Cohorts & \\
\hline ESTHER & DIANA \\
$(n=1045)$, & $(n=1101)$,
\end{tabular}

\begin{tabular}{llc} 
Baseline characteristics & $\mathbf{N}(\%)^{*}$ & $\mathbf{N}(\%)^{*}$ \\
\hline CRP (mg/L) & & \\
$\quad \leq 3$ & $606(58.0)$ & $658(59.8)$ \\
$>3-\leq 10$ & $338(32.3)$ & $349(31.7)$ \\
$>10$ & $101(9.7)$ & $94(8.5)$ \\
\hline D-ROM (Carr unit) & & \\
$\quad \leq 400$ & $805(77.0)$ & $677(61.5)$ \\
$>400$ & $240(23.0)$ & $425(38.5)$ \\
\hline
\end{tabular}

*Numbers shown were drawn from a data set with imputed missing values.

†Definition of low, medium and high education were $\leq 9,10-11$ and $\geq 12$ years of school education, respectively.

$\ddagger$ Definition of low alcohol consumption: women $>0-<20$ and men $>0-<40 \mathrm{~g}$ ethanol per day. Definition of moderate alcohol consumption: women $\geq 20-<40$ and men $\geq 40-<60$ g ethanol per day. Definition of high alcohol consumption: women $\geq 40$ and men $\geq 60 \mathrm{~g}$ ethanol per day.

$\S$ Inactive: 0 hour of vigorous physical activity/week; active: $>0$ hour of vigorous physical activity/week.

TRenal dysfunction was defined by an eGFR $<60 \mathrm{~mL} / \mathrm{min} / 1.73 \mathrm{~m}^{2}$. $\mathrm{BMI}$, body mass index; CRP, C reactive protein; DIANA, Diabetes mellitus: Neue Wege der Optimierung der allgemeinärztlichen Betreuung; D-ROM, Diacron's reactive oxygen metabolites; eGFR, estimated glomerular filtration rate; ESTHER, Epidemiologische Studie zu Chancen der Verhütung, Früherkennung und optimierten Therapie chronischer Erkrankungen in der älteren Bevölkerung; $\mathrm{HbA}_{1 \mathrm{c}}$, glycated haemoglobin A1c; HDL, high-density lipoprotein.

Furthermore, we selected important T2DM-related variables. Data on diabetes medication were obtained from the reported medication of both the participants' and the physicians' questionnaires. The year of diabetes diagnosis was recorded from the participant's questionnaire, and the time since diabetes diagnosis was calculated. In both studies, hemoglobin $\mathrm{A}_{1 \mathrm{c}}\left(\mathrm{HbA}_{1 c}\right)$ was measured from full blood with high performance liquid chromatography (HPLC) methods certified by the National Glycohemoglobin Standardisation Program. In the ESTHER study, the Bio-Rad Variant II (Bio-Rad Laboratories, Hercules, California, USA) and in the DIANA study, the G8 HPLC Analyzer (Tosoh Biosciences, Griesheim (Darmstadt), Germany) were used.

Further serum biomarkers were selected as potential determinants of D-ROM levels, and all analytes were purchased from Roche Diagnostics, Mannheim, Germany. Total and high-density lipoprotein (HDL) cholesterol were assessed by enzymatic colorimetric tests (analytes ESTHER: Chol2 2100 and HDLC3 450; analytes DIANA: CHOL and HDL-C plus third generation). C reactive protein (CRP) was determined by immunoturbidimetry on a Cobas 8000 C701 (analyte in both studies: CRPL3). Serum creatinine was measured by the kinetic Jaffé method on a Cobas 8000 C701 (analyte ESTHER:
CREJ2 3000; analyte DIANA: CREA plus). The estimated glomerular filtration rate (eGFR) was calculated with the creatinine-based Chronic Kidney Disease Epidemiology Collaboration equation, and an eGFR $<60 \mathrm{~mL} / \mathrm{min} / 1.73$ $\mathrm{m}^{2}$ was considered to indicate renal dysfunction. ${ }^{18}$

\section{Statistical analysis}

All statistical analyses were carried out with SAS (Statistical Analysis System) V.9.4, and all tests were performed two sided using an $\alpha$-level of 0.05 unless stated otherwise. The proportion of missing values was below $2 \%$ for all variables except time since diabetes diagnosis, which had $18 \%$ of missing values in the ESTHER cohort. Multiple imputation of five data sets was undertaken to deal with missing values assumed to be missing at random, and the results of these five imputed datasets were combined by the SAS procedure PROC MIANALYZE. All analyses were first carried out separately in both cohorts and pooled by random effects meta-analyses thereafter. Meta-analyses were conducted with the Comprehensive Meta-Analysis 2.0 software (Biostat, Englewood, New Jersey, USA).

\section{Cross-sectional analysis}

Generalized linear models (GLMs) were used to assess the association of categorized or binary modeled factors with continuously modeled D-ROM at designated baselines of the two studies. Backwards selection was used in both studies to remove non-significant variables with an $\alpha$-level $\geq 0.1$. To derive the final model, previously excluded variables were added again if they were associated with D-ROM levels with an $\alpha$-level $<0.1$ in one but not in the other study because they could be statistically significant $(\mathrm{p}<0.05)$ in the meta-analysis. Meta-analyses with random effects were chosen to acknowledge between-study heterogeneity. In addition, the finally selected variables from the GLM analysis were also used for a logistic regression analysis to obtain ORs with $95 \%$ CIs for a dichotomous outcome of high OS defined by D-ROM levels $>400$ Carr U (reference group: D-ROM levels $\leq 400$ ). The obtained ORs from the two cohorts were also pooled by random effects meta-analysis. CRP was not included in the main analysis due to its high correlation with D-ROM levels. Instead, we conducted a sensitivity analysis in which the final model was adjusted for CRP.

\section{Longitudinal analysis}

The statistical methods for the longitudinal analysis were analogous to those of the cross-sectional analysis. The only differences were the following:

1. The dependent variable in the GLM analysis was the change $(\Delta)$ in D-ROM concentrations observed from the chosen baseline to the FU 3 years (ESTHER study) or 4 years (DIANA study) after baseline.

2. The dependent variable in the logistic regression analysis was D-ROM levels in the FU >400 Carr U (reference group: D-ROM levels $\leq 400$ ). All participants with baseline D-ROM concentrations $>400$ Carr $\mathrm{U}$ were fil- 
tered out from this analysis in order to analyze only incident cases of high OS.

3. All models were adjusted for baseline D-ROM concentrations.

\section{RESULTS}

Baseline characteristics of the included patients with T2DM of the ESTHER diabetes subcohort and the DIANA study are shown in table 1 . With few exceptions, most of the baseline characteristics' distributions were comparable. While the DIANA study sample included more study participants younger than 60 years, the proportion of individuals aged 60-70 years was higher in the ESTHER study. Presumably due to the age difference, on average, the DIANA study participants were more frequently physically active and had more frequently HDL levels $<40 \mathrm{mg} / \mathrm{L}$. In the ESTHER sample, more patients with T2DM were rather recently diagnosed with diabetes in the last 5 years, had more frequently an $\mathrm{HbA}_{1 \mathrm{c}}$ $<7 \%$ and were more frequently non-pharmacologically treated. These differences can be explained by the fact that the ESTHER study population was recruited during a health check-up that screened for undiagnosed diabetes, and therefore the ESTHER study includes more patients with early-stage T2DM. In line with this, the proportion of T2DM patients with high OS, defined by D-ROM levels $>400$ Carr units, was lower in the ESTHER study (23.0\%) than in the DIANA study $(38.5 \%)$.

In the following text, the results of the cross-sectional analyses with a continuous and dichotomous dependent D-ROM variable (table 2) as well as the longitudinal analyses with a continuous and dichotomous dependent D-ROM variable (table 3 ) are being summarized by potential risk factors, starting with age. The tables only show the results for potential risk factors, which were associated with D-ROM levels with an $\alpha$-level $<0.1$ in at least one of the two studies. All other factors listed in table 1 but not in table 2 or table 3 were removed from the multivariable model because they were not associated with D-ROM levels ( $\alpha$-level $\geq 0.1$ in both studies). In the text, we focus on the results from the meta-analysis of two cohort studies. Results from the two individual cohorts are shown in online supplementary tables 1-4.

\section{Age}

In the cross-sectional analysis, age was not associated with D-ROM levels. However, in the longitudinal analysis, the risk of higher OS increased with increasing age. The odds of having high OS was $50 \%$ and $74 \%$ higher in the age groups $70-<80$ years and $\geq 80$ years, respectively, compared with the age group younger than 60 years (table 3 ).

\section{Sex}

Female sex was one of the factors most strongly associated with OS in both the cross-sectional and longitudinal analyses. The odds of having high OS were more than fourfold and twofold increased for women compared with men in cross-sectional and longitudinal analysis, respectively (tables 2-3).

\section{Education}

Twelve or more years of school education were statistically significantly associated with lower odds of high OS in the cross-sectional logistic regression model. Individuals with $\geq 12$ years of school education had $43 \%$ lower odds of having high OS compared with those with $\leq 9$ years of education (table 2). However, the results did not resonate in the longitudinal models.

\section{Body mass index}

T2DM patients with a BMI $\geq 40 \mathrm{~kg} / \mathrm{m}^{2}$ had significantly higher odds of high OS in all cross-sectional and longitudinal analyses. The logistic model results even showed statistically significant ORs in all obesity groups from 30 $\mathrm{kg} / \mathrm{m}^{2}$ and above. In cross-sectional analysis, compared with participants with $<25 \mathrm{~kg} / \mathrm{m}^{2}$, the OR point estimates for high OS were 1.35, 1.64 and 2.83 for the BMI groups $30-<35,35-<40$ and $\geq 40 \mathrm{~kg} / \mathrm{m}^{2}$, respectively (table 2 ). These corresponding ORs from the longitudinal analysis were comparable: 1.50, 1.74 and 2.12 (table 3).

\section{Smoking}

Current heavy smokers ( $>15 \mathrm{~g}$ tobacco/day) had higher odds of having high D-ROM levels as compared with nonsmokers in all cross-sectional and longitudinal analyses. More than twofold and up to 1.5-fold increased odds of OS was detected for current smokers in the cross-sectional and longitudinal analysis, respectively (tables 2-3). Weaker but also statistically significant 1.2-fold and 1.3fold increased odds for high OS were also observed for former smokers in the cross-sectional and longitudinal analysis, respectively (tables $2-3$ ).

\section{Alcohol consumption}

Alcohol consumption was only statistically significantly associated with D-ROM levels $>400$ Carr $\mathrm{U}$ in the longitudinal analysis. Interestingly, whereas moderate alcohol consumers had a $56 \%$ lower odds of high D-ROM compared with abstainers, T2DM patients with high alcohol consumption had more than twofold odds of high OS (table 3).

\section{Physical activity}

Like alcohol consumption, physical activity was also only associated with OS in the prospective analysis. As expected, people engaging in physical activity had significantly lower odds of OS. The effect estimate was statistically significant in the GLM model and close to statistical significance in the logistic regression model (table 3).

\section{Vegetable and fruits consumption}

Neither vegetable nor fruits consumption habits were associated with D-ROM levels in any of the multivariable models.

\section{Hemoglobin $\mathrm{A}_{1}$}

An $\mathrm{HbA}_{1 \mathrm{c}} \geq 7 \%$ was statistically significantly associated with slightly increased odds of OS in the cross-sectional 
Table 2 Factors associated with oxidative stress cross-sectionally

\begin{tabular}{|c|c|c|c|}
\hline \multirow[b]{2}{*}{ Parameter } & \multicolumn{2}{|c|}{$\begin{array}{l}\text { GLM results with continuous D-ROM as } \\
\text { dependent variable }\end{array}$} & \multirow{2}{*}{$\begin{array}{l}\text { Logistic regression results } \\
\text { with } \mathrm{D}-\mathrm{ROM}>400 \text { Carr U } \\
\text { as dependent variable } \\
\text { OR }(95 \% \mathrm{Cl})\end{array}$} \\
\hline & B & $P$ value & \\
\hline Sex & 55.17 & $<0.01$ & 4.64 (4.16 to 5.16$)$ \\
\hline \multicolumn{4}{|l|}{ Education } \\
\hline Low & Ref & & Ref \\
\hline Medium & 2.66 & 0.54 & 1.12 (0.99 to 1.27$)$ \\
\hline High & -5.81 & 0.27 & 0.57 (0.47 to 0.68$)$ \\
\hline \multicolumn{4}{|l|}{ BMI $\left(\mathrm{kg} / \mathrm{m}^{2}\right)$} \\
\hline$<25$ & Ref & & Ref \\
\hline $25-<30$ & -4.93 & 0.29 & 1.13 (0.98 to 1.31$)$ \\
\hline $30-<35$ & 1.76 & 0.72 & 1.35 (1.16 to 1.57$)$ \\
\hline $35-<40$ & 7.02 & 0.27 & 1.64 (1.35 to 1.98$)$ \\
\hline$\geq 40$ & 26.59 & 0.001 & 2.83 (2.25 to 3.55$)$ \\
\hline \multicolumn{4}{|l|}{ Smoking } \\
\hline Never smoker & Ref & & Ref \\
\hline Former smoker & 3.46 & 0.32 & 1.20 (1.08 to 1.34$)$ \\
\hline $\begin{array}{l}\text { Current smoker, smoking } 0-15 \mathrm{~g} \\
\text { tobacco/day }\end{array}$ & 30.09 & $<0.01$ & 2.23 (1.82 to 2.74$)$ \\
\hline $\begin{array}{l}\text { Current smoker, smoking }>15 \mathrm{~g} \\
\text { tobacco/day }\end{array}$ & 24.65 & $<0.01$ & 2.17 (1.76 to 2.68 ) \\
\hline \multicolumn{4}{|l|}{$\mathrm{HbA}_{1 \mathrm{c}}(\%)$} \\
\hline$<6$ & Ref & & Ref \\
\hline $6-<7$ & 1.48 & 0.73 & 1.06 (0.93 to 1.21$)$ \\
\hline $7-<8$ & 10.35 & 0.04 & 1.32 (1.12 to 1.54$)$ \\
\hline$\geq 8$ & 4.08 & 0.53 & 1.38 (1.13 to 1.68$)$ \\
\hline \multicolumn{4}{|l|}{ Diabetes medication } \\
\hline No & Ref & & Ref \\
\hline Oral antidiabetics & -15.50 & $<0.01$ & 0.57 (0.51 to 0.63$)$ \\
\hline Insulin & -7.95 & 0.09 & $0.71(0.62$ to 0.82$)$ \\
\hline History of stroke & -11.71 & 0.03 & 0.85 (0.72 to 1.02$)$ \\
\hline History of myocardial infarction & 7.45 & 0.20 & 1.31 (1.08 to 1.56$)$ \\
\hline Coronary heart disease & 4.24 & 0.33 & 1.05 (0.91 to 1.20$)$ \\
\hline Heart failure & 15.10 & $<0.01$ & $1.42(1.25$ to 1.62$)$ \\
\hline History of cancer & 13.74 & $<0.01$ & 1.50 (1.31 to 1.73$)$ \\
\hline \multicolumn{4}{|l|}{ Total cholesterol (mg/dL) } \\
\hline$<200$ & Ref & & Ref \\
\hline $200-<280$ & 11.86 & $<0.01$ & 1.32 (1.19 to 1.47$)$ \\
\hline$\geq 280$ & 18.77 & $<0.01$ & $1.54(1.32$ to 1.80$)$ \\
\hline
\end{tabular}

Pooled effect estimates from the ESTHER type 2 diabetes subcohort $(n=1045)$ and the DIANA study $(n=1101)$.

All variables shown in the table were assessed simultaneously in the same multivariable model. Numbers shown were generated from a data set with imputed missing values.

Results in bold highlight statistically significant findings $(P<0.05)$.

BMI, body mass index; DIANA, Diabetes mellitus: Neue Wege der Optimierung der allgemeinärztlichen Betreuung; D-ROM, Diacron's reactive oxygen metabolites ; ESTHER, Epidemiologische Studie zu Chancen der Verhütung, Früherkennung und optimierten Therapie chronischer Erkrankungen in der älteren Bevölkerung; GLM, generalized linear model; $\mathrm{HbA}_{1 \mathrm{c}}$, glycated haemoglobin $\mathrm{A}_{1 \mathrm{c}}$.

analysis (OR point estimates were 1.32 and 1.38 for the $\mathrm{HbA}_{1 \mathrm{c}}$ groups ' $7 \%-<8 \%$ ' and ' $\geq 8 \%$ ', respectively; table 2). In contrast, baseline $\mathrm{HbA}_{1 \mathrm{c}}$ was not associated with FU D-ROM levels.

\section{Diabetes medication}

Compared with those patients with T2DM not treated with antidiabetic drugs, both users of oral antidiabetics and insulin had statistically significantly lower 
Table 3 Factors associated with oxidative stress longitudinally

\begin{tabular}{|c|c|c|c|}
\hline \multirow[b]{2}{*}{ Parameter } & \multicolumn{2}{|c|}{$\begin{array}{l}\text { GLM results with } \\
\text { continuous } \Delta \mathrm{D}-\mathrm{ROM} \text { as } \\
\text { dependent variable }\end{array}$} & \multirow{2}{*}{$\begin{array}{l}\text { Logistic regression results with } \\
\text { follow-up D-ROM }>400 \text { Carr U } \\
\text { as dependent variable } \\
\text { OR }(95 \% \mathrm{Cl})\end{array}$} \\
\hline & B & $P$ value & \\
\hline \multicolumn{4}{|l|}{ Age (years) } \\
\hline$<60$ & Ref & & Ref \\
\hline $60-<70$ & 6.96 & 0.17 & 1.22 (0.97 to 1.54$)$ \\
\hline $70-<80$ & 9.68 & 0.07 & 1.50 (1.19 to 1.88$)$ \\
\hline$\geq 80$ & 15.62 & 0.03 & 1.74 (1.26 to 2.41$)$ \\
\hline Female sex & 14.79 & $<0.01$ & 2.12 (1.75 to 2.56$)$ \\
\hline \multicolumn{4}{|l|}{ BMI $\left(\mathrm{kg} / \mathrm{m}^{2}\right)$} \\
\hline$<25$ & Ref & & Ref \\
\hline $25-<30$ & -3.37 & 0.45 & 0.93 (0.76 to 1.14$)$ \\
\hline $30-<35$ & -1.67 & 0.72 & $0.79(0.64$ to 0.97$)$ \\
\hline $35-<40$ & 10.10 & 0.10 & 1.94 (1.48 to 2.54$)$ \\
\hline$\geq 40$ & 16.94 & 0.03 & 1.78 (1.25 to 2.52$)$ \\
\hline \multicolumn{4}{|l|}{ Smoking } \\
\hline Never smoker & Ref & & Ref \\
\hline Former smoker & 1.61 & 0.63 & 1.34 (1.15 to 1.56$)$ \\
\hline $\begin{array}{l}\text { Current smoker, smoking } 0-15 \mathrm{~g} \\
\text { tobacco/day }\end{array}$ & 10.43 & 0.15 & 1.39 (1.03 to 1.88$)$ \\
\hline $\begin{array}{l}\text { Current smoker, smoking }>15 \mathrm{~g} \\
\text { tobacco/day }\end{array}$ & 17.56 & 0.02 & $1.56(1.11$ to 2.19$)$ \\
\hline \multicolumn{4}{|l|}{ Alcohol consumption } \\
\hline Abstainer & Ref & & Ref \\
\hline Low consumption & 4.21 & 0.19 & 1.04 (0.90 to 1.20$)$ \\
\hline Moderate consumption & -0.38 & 0.96 & 0.54 (0.38 to 0.77$)$ \\
\hline High consumption & 14.35 & 0.25 & 2.09 (1.18 to 3.70$)$ \\
\hline Physical activity (active) & -6.77 & 0.03 & $0.86(0.75$ to 1.00$)$ \\
\hline \multicolumn{4}{|l|}{ Diabetes medication } \\
\hline No & Ref & & Ref \\
\hline Oral antidiabetics & 0.32 & 0.93 & $0.89(0.76$ to 1.04$)$ \\
\hline Insulin & 10.45 & 0.03 & 1.20 (0.97 to 1.45$)$ \\
\hline \multicolumn{4}{|l|}{ Time since diabetes diagnosis (years) } \\
\hline$<5$ & Ref & & Ref \\
\hline $5-<10$ & -4.13 & 0.29 & $1.33(1.34$ to 1.57$)$ \\
\hline $10-<20$ & -1.76 & 0.67 & $1.24(1.03$ to 1.48$)$ \\
\hline$\geq 20$ & -5.74 & 0.40 & 1.25 (0.95 to 1.65$)$ \\
\hline Baseline D-ROM (per 10 Carr units) & -4.71 & $<0.01$ & 1.21 (1.19 to 1.22$)$ \\
\hline
\end{tabular}

Pooled effect estimates from the ESTHER type 2 diabetes subcohort $(n=731)$ and the DIANA study $(n=740)$.

All variables shown in the table were assessed simultaneously in the same multivariable model. Numbers shown were generated from a data set with imputed missing values.

Results in bold highlight statistically significant findings $(\mathrm{P}<0.05)$.

BMI, body mass index; DIANA, Diabetes mellitus: Neue Wege der Optimierung der allgemeinärztlichen Betreuung; D-ROM, Diacron's reactive oxygen metabolites; ESTHER, Epidemiologische Studie zu Chancen der Verhütung, Früherkennung und optimierten Therapie chronischer Erkrankungen in der älteren Bevölkerung; GLM, generalized linear model.

D-ROM levels (table 2). However, the picture was completely different in the longitudinal analysis. Oral antidiabetics use was not associated with future D-ROM levels, and insulin use was associated with higher odds of OS at FU (statistically significant in
GLM model and close to statistical significance in the logistic regression model (table 3 ).

Time since diabetes diagnosis

Results for the time since diabetes diagnosis, which is an imprecise proxy for the state of the progression of 
the disease, were not statistically significant in the crosssectional analysis. However, patients with T2DM, who were recently diagnosed (ie, in the last 5 years). had slightly lower odds of high OS in the future than patients with T2DM who have already lived with the disease for a longer time (table 3).

\section{Diseases}

None of the assessed diseases or past disease events were associated with OS in the longitudinal analyses. Moreover, renal dysfunction, hypertension and CHD were not statistically significantly associated with OS in the crosssectional analyses. In contrast, patients with heart failure, a previous MI or a history of cancer had statistically significantly 1.3-fold, 1.4-fold and 1.5-fold increased odds of high OS, respectively (table 2). In addition, a history of stroke was statistically significantly associated with lower OS in the GLM model and on the border to statistical significance in the logistic regression model (table 2 ).

\section{Total and HDL cholesterol}

In the cross-sectional analysis, T2DM patients with increased total cholesterol levels $\geq 200 \mathrm{mg} / \mathrm{dL}$ had higher odds of increased D-ROM levels (table 2). However, total cholesterol was not significantly associated with OS in the prospective analysis. HDL cholesterol was neither associated with OS in the cross-sectional nor longitudinal analysis.

\section{$C$ reactive protein}

CRP was added to the final models in a sensitivity analysis. The known high correlation with D-ROM levels manifested in very high $B$-coefficients for the associations of increased CRP levels with D-ROM concentrations (online supplementary tables 5-6). However, B-coefficients were strongly attenuated in the longitudinal analysis and only subclinical inflammation (CRP $>3-\leq 10 \mathrm{mg}$ / dL) remained statistically significantly associated with D-ROM levels. Effect estimates for the other covariates of the model were mostly similar or slightly attenuated in the CRP adjusted models. The only noteworthy changes were observed for the association of high BMI and high $\mathrm{HbA}_{1 c}$ with D-ROM levels, which were strongly attenuated and lost statistical significance.

\section{DISCUSSION}

In the current meta-analysis of two distinct T2DM cohorts from Germany, female sex, low education, obesity, smoking, high total cholesterol, $\mathrm{HbA}_{1 \mathrm{c}} \geq 7 \%$, no diabetes medication, a history of MI, heart failure, a history of cancer and CRP $>3 \mathrm{mg} / \mathrm{L}$ were statistically significantly associated with higher D-ROM levels cross-sectionally. The longitudinal meta-analysis revealed that old age, female sex, obesity, smoking, high alcohol consumption, $\geq 5$ years since diabetes diagnosis and subclinical inflammation (CRP 3- $\leq 10 \mathrm{mg} / \mathrm{L}$ ) were associated with increased D-ROM levels. In the following discussion, we put these findings into context with results from other studies and discuss potential mechanisms and prevention measures.

Age

Higher age was associated with elevated OS in the longitudinal but not in the cross-sectional analysis of our study. A recent cross-sectional study with 126 T2DM and hypertensive adults assessed the associations of age with different OS markers, namely 8-hydroxy-2-deoxyguanosine (8-OH-dG) and malondialdehyde (MDA).$^{19} \mathrm{MDA}$ is a lipid peroxidation biomarker like D-ROM and was also not associated with age, which is in agreement with our cross-sectional findings. However, 8-OH-dG, which is a biomarker for DNA oxidation, was associated with age. No comparable longitudinal study has been published so far. In summary, the cross-sectional relationship of age and OS may depend on the OS biomarker chosen. However, there is consensus in the scientific literature that age is associated with increased OS levels, ${ }^{20}{ }^{21}$ a hypothesis, which was once more supported by our longitudinal analysis. As OS is known to be a driving force in T2DM and related complications, ${ }^{22}$ preventive efforts against high OS should have a specific focus on older patients with T2DM.

\section{Sex}

Female sex was particularly strongly associated with high OS in our cohorts, suggesting that older women with T2DM are being more vulnerable toward the hazards of OS than men. The impact of female sex on OS biomarker levels depends on the estrogen blood concentrations and thus on menopausal status. ${ }^{23}$ While a small study in healthy adults aged 20-39 years reported that premenopausal women have lower OS levels than men, ${ }^{24}$ a different study in adults aged $50-75$ years found perimenopausal and postmenopausal women prone to higher OS than men. ${ }^{25}$ Most of the participants of the ESTHER and DIANA study included in our study were 50 years and older indicating the inclusion of mostly perimenopausal and postmenopausal women ${ }^{26}$ in our study. This explains the observed association of female sex with high OS in our study. Likewise, a cross-sectional study from Japan with 100 on average 59-year-old patients with type 2 diabetes observed significantly higher D-ROM levels in women than men. ${ }^{27} \mathrm{~A}$ hormone replacement therapy (HRT) may be considered after a thorough riskbenefit evaluation for each individual perimenopausal or postmenopausal woman with T2DM who is experiencing high OS because there is evidence from many clinical trials that HRT is effective in lowering various OS biomarkers. ${ }^{28-30}$

\section{Education}

Low education status, as a proxy for the socioeconomic status, was shown to be associated with higher OS and lower antioxidant potential in cross-sectional as well as longitudinal analyses in a previous study. ${ }^{31}$ However, this study only adjusted for age, sex, race and BMI and 
observed that the potential effect of education on OS was mediated by smoking, drinking and symptoms of depression. This implies that the socioeconomic status is likely not causally related to OS and is rather related to other important lifestyle or disease-oriented OS risk factors. This would be in line with our finding of education not being a predictor of high OS and speaks against a causal relationship.

\section{Body mass index}

A significant association between obesity and higher D-ROM levels was consistently observed in our analyses with patients with diabetes. However, this result might be specific for patients with diabetes because we recently showed with longitudinal data from the total ESTHER study that BMI was not associated with D-ROM levels. ${ }^{32}$ However, another biomarker for OS (total thiol levels) was significantly associated with BMI in the total ESTHER population $^{32}$ and various other studies using urinary 8-epi-prostaglandin F2 $\alpha$, a different biomarker of lipid peroxidation, also observed associations of BMI with higher OS. ${ }^{33}{ }^{34}$ Visceral body fat is known to generate proinflammatory cytokines like tumor necrosis factor- $\alpha$, interleukin (IL)-1, and IL-6, which augment OS by increased generation of ROS and nitrogen. ${ }^{35}$ This mechanism via inflammation can also explain why BMI lost its statistical significant association with D-ROM levels after adjusting the model for the acute phase inflammatory protein CRP. In line with these thoughts, caloric restriction has been linked with the reduction of OS and healthy aging. ${ }^{36}$ Thus, prevention measures targeting weight loss in persons with pronounced abdominal adiposity might be helpful to regulate an unfavorable OS status. In addition, prevention strategies against adiposity before its onset in earlier life can also be recommended.

\section{Smoking}

There is considerable evidence from previous studies about a strong relationship of current smoking with high OS. ${ }^{2}{ }^{37}$ Our study adds to this existing knowledge by confirming this association in T2DM individuals. In addition, we also observed a weak association of former smoking with OS, which has also been detected by others before. ${ }^{38}$ An association of past smoking with OS is not a biologically plausible finding and might be explained by misclassification of smoking status in the cross-sectional analysis by falsely self-reported smoking status, a reuptake of smoking of some former smokers during the FU or by residual confounding. In contrast, the strong association of current smoking and OS is clinically plausible. A smoker consumes approximately $10^{17}$ oxidant molecules from each puff of cigarette smoke. ${ }^{39}$ Additionally, the direct damage by superoxide and hydrogen peroxide radical species and the corresponding inflammatory response induced during smoking can lead to higher OS in smokers. ${ }^{40}$ Subsequently, smoking cessation, which is to be recommended for a large variety of health outcomes, might also help to prevent or treat high OS.

\section{Alcohol consumption}

We observed that high alcohol consumption was associated with increased odds of OS in the prospective analysis. This increased risk could be attributed to the metabolism of ethanol, which is directly involved in the production of ROS and reactive nitrogen substances (RNS) and subsequently a decrease in the concentrations of antioxidative proteins. ${ }^{41}$ Furthermore, ethanol metabolism can induce fatty acids oxidation in phospholipids, ${ }^{42}$ which can especially explain the association with D-ROM, which is a biomarker for lipid peroxidation. In contrast, moderate alcohol consumption was inversely associated with high OS in our longitudinal study. A potential explanation for this finding may be resveratrol in wine, whose antioxidative and anti-inflammatory actions are well established. ${ }^{43}$ For example, a small study among Australian adults consuming $40 \mathrm{~mL}$ of red wine per day for 2 weeks reported significantly elevated antioxidant status and decreased OS. ${ }^{44}$ Taken together, the potential effect of alcohol consumption on OS may be dose dependentmoderate doses may reduce OS, while higher doses may increase OS. This leads us to the recommendation that high alcohol consumption should be reduced for various health reasons, of which high OS is only one. However, subjects with high OS status and no contraindication for moderate alcohol consumption (liver disease or any addiction disorder) might profit from the consumption of low amounts of red wine (up to 1-2 glasses per day). ${ }^{45}$

\section{Physical activity}

We demonstrated that physically active T2DM subjects had reduced odds of having high OS. Likewise, studies have inferred similar results for young and old individuals from the general population ${ }^{46}{ }^{47}$ as well as for patients with T2DM. ${ }^{48}$ Exercise induces ROS generation, which subsequently activates nuclear factor erythroid 2 signaling, which in turn increases the expression of antioxidant enzymes. ${ }^{48}$ Thus, regularly performed physical activity strengthens the antioxidant defense system. Therefore, we agree with other experts that regular physical activity should be highly recommended for patients with T2DM in order to improve their antioxidant status. ${ }^{49}$

\section{Vegetable and fruits consumption}

Vegetables and fruits contain high concentrations of antioxidative nutrients, which in turn can scavenge ROS. ${ }^{50}$ Among the most important antioxidants are fibers, polyphenols, flavonoids, vitamins $\mathrm{A}, \mathrm{B}, \mathrm{C}$ and $\mathrm{E}$ and tocopherols. ${ }^{51}$ Although a study in 54 patients with T2DM detected a significant association between high intakes of fruit and vegetables with decreased $\mathrm{OS}^{52}{ }^{52}$ we failed to detect the same among our study participants. The lack of an association with D-ROM levels in the DIANA and ESTHER study may be explained by the imprecise assessment of nutrition. Other studies with detailed food frequency questionnaires observed protective effects of fruit and vegetable intake against high $\mathrm{OS}^{53}{ }^{54}$ Generally, a change of diet with higher fruits and vegetable 
consumption and less red meat consumption, which is already being recommended for all patients with T2DM, should be particularly emphasized as a recommendation for T2DM patients with high OS. Possibly, communication of high OS biomarker results to these patients can help to motivate them to change their diet.

\section{Hemoglobin $\mathrm{A}_{\text {, }}$}

We observed that T2DM patients with $\mathrm{HbA}_{1 \mathrm{c}} \geq 7 \%$ had higher OS than study participants with lower $\mathrm{HbA}_{1 \mathrm{c}}$, which is in line with the results of a small study from Saudi Arabia, which used another biomarker of lipid peroxidation (malondialdehyde (MDA) ). ${ }^{55}$ However, in our study, this cross-sectional association disappeared after adjusting for CRP, and moreover, no association of $\mathrm{HbA}_{1 \mathrm{c}}$ and D-ROM levels was detected in the longitudinal analysis. These findings speak against hyperglycemia as an independent risk factor for high OS in patients with T2DM.

\section{Diabetes medication}

Substantially lower D-ROM levels were observed in patients with T2DM treated with oral antidiabetics compared with non-treated T2DM patients. In a previous analysis with the ESTHER diabetes subpopulation and the DIANA study, we observed that the lower D-ROM levels of oral antidiabetic drug users was attributable to the metformin users. ${ }^{10}$ This is in agreement with results from trials with a metformin intervention. ${ }^{56} 57$ A plausible mechanism is the lipid-lowering effect of metformin, which can ultimately lead to lower levels of lipid peroxidation biomarkers. ${ }^{10}$ With regards to insulin therapy, our results for the cross-sectional (inverse association) and longitudinal analysis (positive association) were contradictory. However, the finding of the longitudinal analysis for insulin use should be treated with caution because the meta-analysis had high heterogeneity as the results from the DIANA study (positive association) and the ESTHER study (null association) did not confirm each other (online supplementary table 3). A clinical trial established evidence that insulin therapy as add-on therapy to oral antidiabetics has a protective effect on OS. ${ }^{58}$ Thus, we think that the finding from the DIANA study showing higher odds of high OS for insulin users was a finding by chance. In summary, our results support the usage of metformin in patients with high OS if the alternative is prescribing of no antidiabetic drugs. Further studies are needed to clarify whether, if oral antidiabetic therapy is not sufficient to control $\mathrm{HbA}_{1 \mathrm{c}}$, insulin add-on therapy may also be an additional option to decrease OS.

\section{Time since diabetes diagnosis}

We hypothesized that time since diabetes diagnosis might be associated with OS because diabetes-related comorbidity increases with time. However, results were not statistically significant in the cross-sectional analysis and weak (but statistically significant) in the longitudinal analysis in our study with patients with T2DM, which might be explained by adjustment for factors in the model, which could be confounders of the association of time since diabetes diagnosis and D-ROM levels (eg, diseases). Similarly, a small cross-sectional study with 42 patients with type 1 diabetes mellitus (T1DM) observed no association of time since diabetes diagnosis with biomarkers of OS. ${ }^{59}$ Although being an important risk factor for mortality in patients with T2DM, ${ }^{60}$ our results do not suggest a strong impact of the time since diabetes diagnosis on the OS status of patients with T2DM.

\section{Diseases}

Several cardiovascular diseases, renal dysfunction and history of cancer were tested for an association with OS, and none of the conditions was longitudinally associated with OS. We would have liked to compare our longitudinal findings for the medical conditions to other studies, but to the best of our knowledge no other comparable studies have been conducted so far. Only heart failure, a history of MI and a history of cancer were associated with high OS in our cross-sectional analysis. A possible explanation might be that T2DM patients with the named comorbidities have increased D-ROM levels, but the comorbidities do not cause increased OS. Several other cross-sectional studies observed increased OS biomarker levels in subjects with CVD or cancer compared with disease-free control subjects. ${ }^{17} 61$ Furthermore, the progression of diabetic nephropathy and dialysis have been found to be associated with increased oxidative damage and decreased antioxidant capacity in previous studies with patients with T2DM. ${ }^{62}$ The lack of an association of D-ROM levels and renal dysfunction in the DIANA and ESTHER study may be attributed to the low number of study participants with severe renal impairment (prevalence of eGFR $<30 \mathrm{~mL} / \mathrm{min} / 1.73 \mathrm{~m}^{2}$ was $1.2 \%$ and $3.2 \%$ in the ESTHER and DIANA study, respectively). Nevertheless, our results support suggestions that early interventions against renal dysfunction and well-managed dialysis (if required) can contribute to homeostasis of OS. ${ }^{62} 63$ Contradictory to a previous, small, cross-sectional study with 100 diabetes patients, which observed an association of D-ROM levels with systolic blood pressure, ${ }^{27}$ we did not observe a relationship of D-ROM levels with hypertension. Furthermore, a previous history of stroke was associated with lower D-ROM levels in our study. However, this association was weak and may be a result of residual confounding.

\section{Total and HDL cholesterol}

We observed an association of elevated total cholesterol levels with D-ROM levels in the cross-sectional analysis but not in the longitudinal analysis. This speaks against a causal relationship between total cholesterol levels and OS. A cross-sectional association can simply be explained by the fact that D-ROM is a biomarker of lipid peroxidation and thus its concentration correlates with the concentration of lipids in the circulatory system. Previous studies have observed a close relationship of biomarkers of lipid peroxidation with hyperlipidemia, but these were 
all cross-sectional studies. ${ }^{276465}$ In line with these doubts regarding a causal relationship, a randomized controlled trial observed no effect for simvastatin treatment on the levels of an OS biomarker. ${ }^{66}$

\section{C reactive protein}

As seen in many previous studies, increased CRP was strongly associated with high D-ROM levels in the crosssectional analysis. ${ }^{67} 68$ It has already been shown that OS can provoke and potentiate inflammatory processes. ${ }^{69}$ Interestingly, we also observed a longitudinal association. This implies that T2DM patients with subclinical inflammation may remain at high risk for high OS in the next years and the OS status may even worsen. Thus, antiinflammatory drugs might also be effective against OS (eg, non-steroidal anti-inflammatory drugs or corticosteroids) though their long-term use would have to carefully weigh potential benefits and harms. The novel interleukin-1B inhibitor canakinumab may be a promising alternative. ${ }^{70}$ However, more clinical trials and evidence from postmarketing surveillance studies about the benefit-risk ratio of long-term therapy with this interesting new drug class are needed before its use can be recommended.

\section{Strengths and limitations}

Our study has several strengths and limitations. To begin with, the prospective design achieved by repeated D-ROM measurements at two time points 3-4 years apart is one of its major plus points. Furthermore, the large sample size went along with a high statistical power enabling us to detect even modest associations. Finally, analyzing two distinct cohort studies and meta-analyzing their results should ameliorate the reproducibility of our results by other studies. We did not adjust for multiple testing because the set of potential determinants of OS was chosen based on a literature search and was not data driven. Furthermore, findings in one cohort, which may have been statistically significant only by chance, could be leveled out in the meta-analysis by the results from the other cohort. Overall, heterogeneity in most of the metaanalyses was low because the T2DM study populations of the two cohorts had similar patient characteristics and harmonized variable definitions were derived, which is an additional strength of our approach.

The main limitation of our study is the observational study design. Residual confounding by unmeasured or less than perfectly measured confounders cannot be excluded (eg, dietary factors). Another limitation is that synthetic antioxidant intake was not investigated in our study. The use of vitamin supplements was largely under-reported in the question about current drug intake in both studies, because presumably vitamins are not regarded as drugs by most Germans (less than 3\% of study participants reported vitamin supplements). As we did not specifically collect information on over-the-counter drug use, we decided not to include the suboptimally determined variable on vitamin supplements use in our models. Furthermore, we cannot completely exclude that a few patients with T1DM are included in the ESTHER T2DM subcohort, because the diabetes type was self-reported and 247 study participants did not report their diabetes type. However, we minimized this risk of including T1DM patients by excluding all subjects with diabetes diagnoses before the 40th birthday. Finally, we would like to state that the study results can only be generalized to Caucasian patients with T2DM, aged 40 years and older.

\section{CONCLUSION}

In this meta-analysis of two German cohort studies of patients with T2DM, we evaluated a comprehensive array of potential risk factors for high OS. For the first time, a longitudinal analysis was performed that allows to establish temporal sequence and deductions on potential causality better than cross-sectional analyses. In this regard, the most important finding is that old age, female sex, obesity, smoking, high alcohol consumption, $\geq 5$ years since diabetes diagnosis and subclinical inflammation were longitudinally associated with increased D-ROM levels over the course of 3-4 years. These results support suggestions that a better management of the modifiable risk factors obesity, smoking, physical inactivity and high alcohol consumption may help to maintain redox balance in patients with T2DM. It is not surprising that these well-known factors for healthy aging appeared in our analysis as potential risk factors for OS. This finding may also explain the recently reported strong association of D-ROM levels with mortality in patients with T2DM. ${ }^{25}$ Taken together, these results suggest regulating these risk factors for high D-ROM levels may help to prolong the average life expectancy of patients with T2DM and to reduce the number of premature deaths.

Acknowledgements The authors would like to thank Piet Beekhof from the Netherlands National Institute for Public Health and the Environment (RIVM) for performing Diacron's reactive oxygen metabolites test measurements.

Contributors AA conducted the statistical analyses. AA wrote the first draft of the paper and BS edited it. EHJMJ contributed to the measurement of the oxidative stress biomarkers. HB, XG, DCL and YX reviewed the manuscript draft and contributed to the interpretation of the results and the discussion.

Funding This study was funded by a grant from the German Research Foundation (grant No. SCHO 1545/3-1). The Epidemiologische Studie zu Chancen der Verhütung, Früherkennung und optimierten Therapie chronischer Erkrankungen in der älteren Bevölkerung (ESTHER) study was funded by grants from the Saarland state Ministry for Social Affairs, Health, Women and Family Affairs (Saarbrücken, Germany), the Baden-Württemberg state Ministry of Science, Research and Arts (Stuttgart, Germany), the Federal Ministry of Education and Research (Berlin, Germany) and the Federal Ministry of Family Affairs, Senior Citizens, Women and Youth (Berlin, Germany). The Diabetes mellitus: Neue Wege der Optimierung der allgemeinärztlichen Betreuung (DIANA) study was funded by a grant from the Federal Ministry of Education and Research (Berlin, Germany).

Disclaimer The funders were not involved in any of the steps in rendering this project be it design, execution, analysis, data interpretation or writing of the manuscript.

Competing interests None declared.

Patient consent for publication Not required.

Ethics approval The protocol of the ESTHER and DIANA study have been approved by the ethics committee of the Medical Faculty of the University of Heidelberg. Moreover, the ESTHER study has been approved by the ethics committee of the 
Medical Association of Saarland and the DIANA study by the ethics committee of the Chamber of Physicians of Baden-Württemberg. Both studies are being conducted in adherence with the declaration of Helsinki and written informed consent has been obtained from all study participants.

Provenance and peer review Not commissioned; externally peer reviewed.

Data availability statement No data are available. The ESTHER and DIANA data cannot be made publicly available due to legal restrictions. However, data can be shared on the basis of research proposals that are in accordance with the study's aims.

Open access This is an open access article distributed in accordance with the Creative Commons Attribution Non Commercial (CC BY-NC 4.0) license, which permits others to distribute, remix, adapt, build upon this work non-commercially, and license their derivative works on different terms, provided the original work is properly cited, appropriate credit is given, any changes made indicated, and the use is non-commercial. See: http://creativecommons.org/licenses/by-nc/4.0/.

ORCID iD

Ben Schöttker http://orcid.org/0000-0002-1217-4521

\section{REFERENCES}

1 Halliwell B. Free radicals, antioxidants, and human disease: curiosity, cause, or consequence? Lancet 1994;344:721-4.

2 Poljsak B. Strategies for reducing or preventing the generation of oxidative stress. Oxid Med Cell Longev 2011;2011:1-15.

3 Asmat U, Abad K, Ismail K. Diabetes mellitus and oxidative stress-A Concise review. Saudi Pharm J 2016;24:547-53.

4 Schöttker B, Xuan Y, Gào X, et al. Oxidatively damaged DNA/RNA and 8-isoprostane levels are associated with the development of type 2 diabetes at older age: results from a large cohort study. Diabetes Care 2020;43:130-6.

5 Black CN, Bot M, Scheffer PG, et al. Sociodemographic and lifestyle determinants of plasma oxidative stress markers 8-OHdG and F2isoprostanes and associations with metabolic syndrome. Oxid Med Cell Longev 2016;2016:1-10.

6 Houstis N, Rosen ED, Lander ES. Reactive oxygen species have a causal role in multiple forms of insulin resistance. Nature 2006;440:944-8.

7 Keane KN, Cruzat VF, Carlessi R, et al. Molecular events linking oxidative stress and inflammation to insulin resistance and $\beta$-cell dysfunction. Oxid Med Cell Longev 2015;2015:181643.

8 Betteridge DJ. What is oxidative stress? Metabolism 2000;49:3-8.

9 Maritim AC, Sanders RA, Watkins JB. Diabetes, oxidative stress, and antioxidants: a review. J Biochem Mol Toxicol 2003;17:24-38

10 Xuan Y, Gào X, Anusruti A, et al. Association of serum markers of oxidative stress with incident major cardiovascular events, cancer incidence, and all-cause mortality in type 2 diabetes patients: pooled results from two cohort studies. Diabetes Care 2019;42:1436-45.

11 Ito F, Ito T, Suzuki C, et al. The application of a modified d-ROMs test for measurement of oxidative stress and oxidized high-density lipoprotein. Int J Mol Sci 2017:18:454.

12 Jansen EHJM, Beekhof PK, Viezeliene D, et al. Long-term stability of oxidative stress biomarkers in human serum. Free Radic Res 2017:51:970-7.

13 Schöttker B, Haug U, Schomburg L, et al. Strong associations of 25-hydroxyvitamin D concentrations with all-cause, cardiovascular, cancer, and respiratory disease mortality in a large cohort study. Am J Clin Nutr 2013;97:782-93.

14 Krämer HU, Raum E, Rüter G, et al. Gender disparities in diabetes and coronary heart disease medication among patients with type 2 diabetes: results from the DIANA study. Cardiovasc Diabetol 2012;11:88.

15 Bock J-O, König $\mathrm{H}-\mathrm{H}$, Brenner $\mathrm{H}$, et al. Associations of frailty with health care costs--results of the ESTHER cohort study. BMC Health Serv Res 2016;16:128.

16 Schöttker B, Saum K-U, Jansen EHJM, et al. Oxidative stress markers and all-cause mortality at older age: a population-based cohort study. J Gerontol A Biol Sci Med Sci 2015;70:518-24.

17 Schöttker B, Brenner H, Jansen EHJM, et al. Evidence for the free radical/oxidative stress theory of ageing from the chances Consortium: a meta-analysis of individual participant data. $B M C$ Med 2015;13:300.

18 Pugliese G, Solini A, Bonora E, et al. Chronic kidney disease in type 2 diabetes: lessons from the renal insufficiency and cardiovascular events (RIACE) Italian multicentre study. Nutr Metab Cardiovasc Dis 2014;24:815-22.
19 Nemtsova V, Bilovol O, Ilchenko I, et al. Age-Associated features of oxidative stress as marker of vascular aging in comorbid course of hypertension and type 2 diabetes mellitus. Vessel Plus 2018;2:27.

20 Sarkar D, Shetty K. Diabetes as a disease of aging, and the role of oxidative stress. In: Aging: oxidative stress and dietary antioxidants, 2014: 61-9.

21 Harman D. Aging: a theory based on free radical and radiation chemistry. J Gerontol 1956;11:298-300.

22 Tiwari BK, Pandey KB, Abidi AB, et al. Markers of oxidative stress during diabetes mellitus. J Biomark 2013;2013:1-8.

23 Doshi SB, Agarwal A. The role of oxidative stress in menopause. $J$ Midlife Health 2013;4:140-6.

24 Ide T, Tsutsui H, Ohashi N, et al. Greater oxidative stress in healthy young men compared with premenopausal women. Arterioscler Thromb Vasc Biol 2002;22:438-42.

25 Xuan Y, Gào X, Holleczek B, et al. Prediction of myocardial infarction, stroke and cardiovascular mortality with urinary biomarkers of oxidative stress: results from a large cohort study. Int J Cardiol 2018:273:223-9.

26 Gold EB. The timing of the age at which natural menopause occurs. Obstet Gynecol Clin North Am 2011;38:425-40.

27 Kotani K, Tsuzaki K, Taniguchi N, et al. Correlation between reactive oxygen metabolites \& atherosclerotic risk factors in patients with type 2 diabetes mellitus. Indian J Med Res 2013;137:742-8.

28 Telci A, Çakatay U, Akhan SE, et al. Postmenopausal hormone replacement therapy use decreases oxidative protein damage. Gynecol Obstet Invest 2002;54:88-93.

29 Escalante Gómez C, Quesada Mora S. HRT decreases DNA and lipid oxidation in postmenopausal women. Climacteric 2013;16:104-10.

30 Sánchez-Rodríguez M, Zacarías-Flores M, Castrejón-Delgado $\mathrm{L}$, et al. Effects of hormone therapy on oxidative stress in postmenopausal women with metabolic syndrome. Int J Mol Sci 2016;17:1388.

31 Janicki-Deverts D, Cohen S, Matthews KA, et al. Socioeconomic status, antioxidant micronutrients, and correlates of oxidative damage: the coronary artery risk development in young adults (cardia) study. Psychosom Med 2009;71:541-8.

32 Anusruti $A$, Jansen EHJM, Gào X, et al. Longitudinal associations of body mass index, waist circumference, and Waist-to-Hip ratio with biomarkers of oxidative stress in older adults: results of a large cohort study. Obes Facts. 2020;27:1-11.

33 Keaney JF, Larson MG, Vasan RS, et al. Obesity and systemic oxidative stress: clinical correlates of oxidative stress in the Framingham study. Arterioscler Thromb Vasc Biol 2003;23:434-9.

34 Fujita K, Nishizawa H, Funahashi T, et al. Systemic oxidative stress is associated with visceral fat accumulation and the metabolic syndrome. Circ J 2006;70:1437-42.

35 Fonseca-Alaniz MH, Takada J, Alonso-Vale MIC, et al. Adipose tissue as an endocrine organ: from theory to practice. J Pediatr (Rio J) 2007;83:S192-203.

36 Heilbronn LK, Ravussin E. Calorie restriction and aging: review of the literature and implications for studies in humans. Am J Clin Nutr 2003;78:361-9.

37 Gao X, Gào X, Zhang Y, et al. Associations of self-reported smoking, cotinine levels and epigenetic smoking indicators with oxidative stress among older adults: a population-based study. Eur J Epidemiol 2017;32:443-56.

38 Donohue JF. Ageing, smoking and oxidative stress. Thorax 2006;61:461-2.

39 Yanbaeva DG, Dentener MA, Creutzberg EC, et al. Systemic effects of smoking. Chest 2007;131:1557-66.

40 Bruno RS, Traber MG. Vitamin E biokinetics, oxidative stress and cigarette smoking. Pathophysiology 2006;13:143-9.

41 Das SK, Vasudevan DM. Alcohol-Induced oxidative stress. Life Sci 2007;81:177-87.

42 Hernández JA, López-Sánchez RC, Rendón-Ramírez A. Lipids and oxidative stress associated with ethanol-induced neurological damage. Oxid Med Cell Longev 2016;2016:1-15

43 Breuss J, Atanasov A, Uhrin P. Resveratrol and its effects on the vascular system. Int J Mol Sci 2019;20:1523.

44 Micallef M, Lexis L, Lewandowski P. Red wine consumption increases antioxidant status and decreases oxidative stress in the circulation of both young and old humans. Nutr J 2007;6:27.

45 Pavlidou E, Mantzorou M, Fasoulas A, et al. Wine: an Aspiring agent in promoting longevity and preventing chronic diseases. Diseases 2018;6:73.

46 Bouzid MA, Filaire E, Matran R, et al. Lifelong voluntary exercise modulates age-related changes in oxidative stress. Int J Sports Med 2018;39:21-8. 
47 Simioni C, Zauli G, Martelli AM, et al. Oxidative stress: role of physical exercise and antioxidant nutraceuticals in adulthood and aging. Oncotarget 2018;9:17181-98.

48 Golbidi S, Badran M, Laher I. Antioxidant and anti-inflammatory effects of exercise in diabetic patients. Exp Diabetes Res 2012;2012:1-16.

49 Teixeira de Lemos E, Oliveira J, Páscoa Pinheiro J, et al. Regular physical exercise as a strategy to improve antioxidant and antiinflammatory status: benefits in type 2 diabetes mellitus. Oxid Med Cell Longev 2012;2012:1-15.

50 Kaur C, Kapoor HC. Antioxidants in fruits and vegetables - the millennium's health. Int J Food Sci Technol 2008;36:703-25.

51 Karakaya S, Kavas A. Antimutagenic activities of some foods. J Sci Food Agric 1999;79:237-42.

52 åsgård R, Rytter E, Basu S, et al. High intake of fruit and vegetables is related to low oxidative stress and inflammation in a group of patients with type 2 diabetes. Scand J Food Nutr 2007;51:149-58.

53 Holt EM, Steffen LM, Moran A, et al. Fruit and vegetable consumption and its relation to markers of inflammation and oxidative stress in adolescents. J Am Diet Assoc 2009;109:414-21.

54 Xie Z, Lin H, Fang R, et al. Effects of a fruit-vegetable dietary pattern on oxidative stress and genetic damage in coke oven workers: a cross-sectional study. Environ Health 2015;14:40.

55 Goodarzi MT, Varmaziar L, Navidi AA, et al. Study of oxidative stress in type 2 diabetic patients and its relationship with glycated hemoglobin. Saudi Med J 2008;29:503-6.

56 Chakraborty A, Chowdhury S, Bhattacharyya M. Effect of metformin on oxidative stress, nitrosative stress and inflammatory biomarkers in type 2 diabetes patients. Diabetes Res Clin Pract 2011;93:56-62.

57 Esteghamati A, Eskandari D, Mirmiranpour $\mathrm{H}$, et al. Effects of metformin on markers of oxidative stress and antioxidant reserve in patients with newly diagnosed type 2 diabetes: a randomized clinical trial. Clin Nutr 2013;32:179-85.

58 Monnier L, Colette C, Mas E, et al. Regulation of oxidative stress by glycaemic control: evidence for an independent inhibitory effect of insulin therapy. Diabetologia 2010;53:562-71.
59 Reis JS, Amaral CAV, Volpe CMO, et al. Oxidative stress and interleukin-6 secretion during the progression of type 1 diabetes. Arq Bras Endocrinol Metabol 2012;56:441-8.

60 Huo L, Magliano DJ, Rancière F, et al. Impact of age at diagnosis and duration of type 2 diabetes on mortality in Australia 1997-2011. Diabetologia 2018;61:1055-63.

61 Masaki N, Sato A, Horii S, et al. Usefulness of the d-ROMs test for prediction of cardiovascular events. Int J Cardiol 2016;222:226-32.

62 Forbes JM, Coughlan MT, Cooper ME. Oxidative stress as a major culprit in kidney disease in diabetes. Diabetes 2008;57:1446-54.

63 Kao MPC, Ang DSC, Pall A, et al. Oxidative stress in renal dysfunction: mechanisms, clinical sequelae and therapeutic options. J Hum Hypertens 2010;24:1-8.

$64 \mathrm{Al}-$ Rawi NH. Oxidative stress, antioxidant status and lipid profile in the saliva of type 2 diabetics. Diab Vasc Dis Res 2011;8:22-8.

65 Yang R-L, Shi Y-H, Hao G, et al. Increasing oxidative stress with progressive hyperlipidemia in human: relation between malondialdehyde and atherogenic index. J Clin Biochem Nutr 2008;43:154-8.

66 Rasmussen ST, Andersen JT, Nielsen TK, et al. Simvastatin and oxidative stress in humans: a randomized, double-blinded, placebocontrolled clinical trial. Redox Biol 2016;9:32-8.

67 Abramson JL, Hooper WC, Jones DP, et al. Association between novel oxidative stress markers and C-reactive protein among adults without clinical coronary heart disease. Atherosclerosis 2005;178:115-21.

68 Cottone S, Mulè G, Nardi E, et al. Relation of C-reactive protein to oxidative stress and to endothelial activation in essential hypertension. Am J Hypertens 2006;19:313-8.

69 Salminen A, Ojala J, Kaarniranta K, et al. Mitochondrial dysfunction and oxidative stress activate inflammasomes: impact on the aging process and age-related diseases. Cell Mol Life Sci 2012;69:2999-3013.

70 Ridker PM, Everett BM, Thuren T, et al. Antiinflammatory therapy with canakinumab for atherosclerotic disease. $N$ Engl J Med 2017;377:1119-31. 